\title{
Erratum to: Recognition and Management of HBV Infection in a Social Context
}

\author{
Haeok Lee • Hie-Won Hann • Jin Hyang Yang • \\ Jacqueline Fawcett
}

Published online: 14 December 2011

(C) Springer Science+Business Media, LLC 2011

\section{Erratum to: J Canc Educ}

\section{DOI 10.1007/s13187-011-0203-5}

In the original publication, the third author's affiliation is incomplete. The full affiliation should read:

\section{J. H. Yang}

Department of Nursing, School of Medicine, Inje University, Busan, South Korea

The online version of the original article can be found at http://dx.doi. org/10.1007/s13187-011-0203-5.

H. Lee $(\bowtie) \cdot$ J. Fawcett

College of Nursing \& Health Sciences,

University of Massachusetts Boston,

100 Morrissey Boulevard,

Boston, MA 02125-3393, USA

e-mail: haeok.lee@umb.edu

J. Fawcett

e-mail: jacqueline.fawcett@umb.edu

H.-W. Hann

Division of Gastroenterology and Hepatology,

Liver Disease Prevention Center,

Jefferson Medical College of Thomas Jefferson University,

Philadelphia, PA, USA

\section{J. H. Yang}

Department of Nursing, School of Medicine, Inje University,

Busan, South Korea 